\title{
Underutilised Resources in Urban Environments
}

\author{
Sigrid Kusch-Brandt ${ }^{1,2}$ (D) \\ 1 Civil, Environmental and Architectural Engineering, University of Padua, 35131 Padua, Italy; \\ mail@sigrid-kusch.eu \\ 2 Water and Environmental Engineering Group, University of Southampton, Southampton SO16 7QF, UK
}

Received: 7 March 2020; Accepted: 2 April 2020; Published: 4 April 2020

\begin{abstract}
An important opportunity for more sustainable development pathways in an urbanising world is missed where resources remain underutilised, when they could be valorised in a sound and environmentally favourable mode. This Special Issue of the journal Resources was initiated to identify promising solutions and specific challenges in the context of underutilised resources in urban environments. The compiled contributions address two main areas, namely the establishment of circular economy schemes based on valorising wastes that occur in urban areas and the exploitation of renewable energies. Circular economy and renewable resources hold key potential for making cities more sustainable, and the authors of this Special Issue, with their publications, enhance our understanding of how to unlock this potential. Effective regulatory frameworks and policymaking processes which balance the powers between stakeholders are required to successfully manage energy transition and the transition to more circular economies. The positive role of community engagement merits high attention. To recover valuable resources from household waste, a focus on technology and infrastructure is required but is not enough; motivational factors and knowledge of citizens are most essential elements. It also becomes evident that the need to more reliably quantify and better characterise recyclable material streams, especially where population numbers are further growing, remains. The publications compiled in this Special Issue are a rich source to identify promising solutions, challenges and research needed for the sound management of urban resource demands.
\end{abstract}

Keywords: urban resources; resource management; sustainable urbanisation; community engagement; circular economy; solid waste recycling; urban energy; renewable energy; energy transition; energy governance; policy-making

\section{Introduction}

With more than half of the world's population already living in urban areas and the global population further rising [1], it is a core challenge of sustainable development endeavours to implement effective schemes for managing resource demands from urban populations in an environmentally sound and economically viable manner [2]. This Special Issue was initiated to explore promising solutions and potential barriers in the context of sustainable management of materials that occur in urban environments or are strongly influenced by urban activities, and, in particular, of materials which today are underutilised. Ten contributions were positively evaluated and included in the Special Issue. The aim of this editorial is to highlight main findings of the publications of the Special Issue and to summarise the key insights.

\section{Towards More Sustainable Urban Resource Management: Insights from the Publications Included in the Special Issue}

Two main focus areas can be identified among the contributions submitted to the Special Issue: valorisation of wastes for the establishment of circular economy schemes and exploitation of renewable 
energies. Table 1 shows that there are interlinkages between circular economy and renewable energy schemes. Seven out of the ten publications address solid wastes and their potential valorisation as part of circular economy schemes [3-9], which can be material recycling or energetic valorisation. Source-segregated waste destined for energetic valorisation is considered a source of renewable energy; four out of the seven manuscripts which address solid wastes are closely linked to renewable energy, and therefore fall into both categories of circular economy and renewable energy. In addition, another work studies the recovery of waste heat from urban infrastructure [10], and thus combines an uncommon circular economy approach based on heat valorisation with the search for more sustainable energy schemes. Two contributions explicitly focus on more widespread adoption of renewable energies in cities [11,12].

Table 1. Overview of publications in the Special Issue 'Underutilised Resources in Urban Environments', listed in the order as they appear on the website of the Special Issue [13] (+++: main focus area of the publication, +: integrated topic of major relevance).

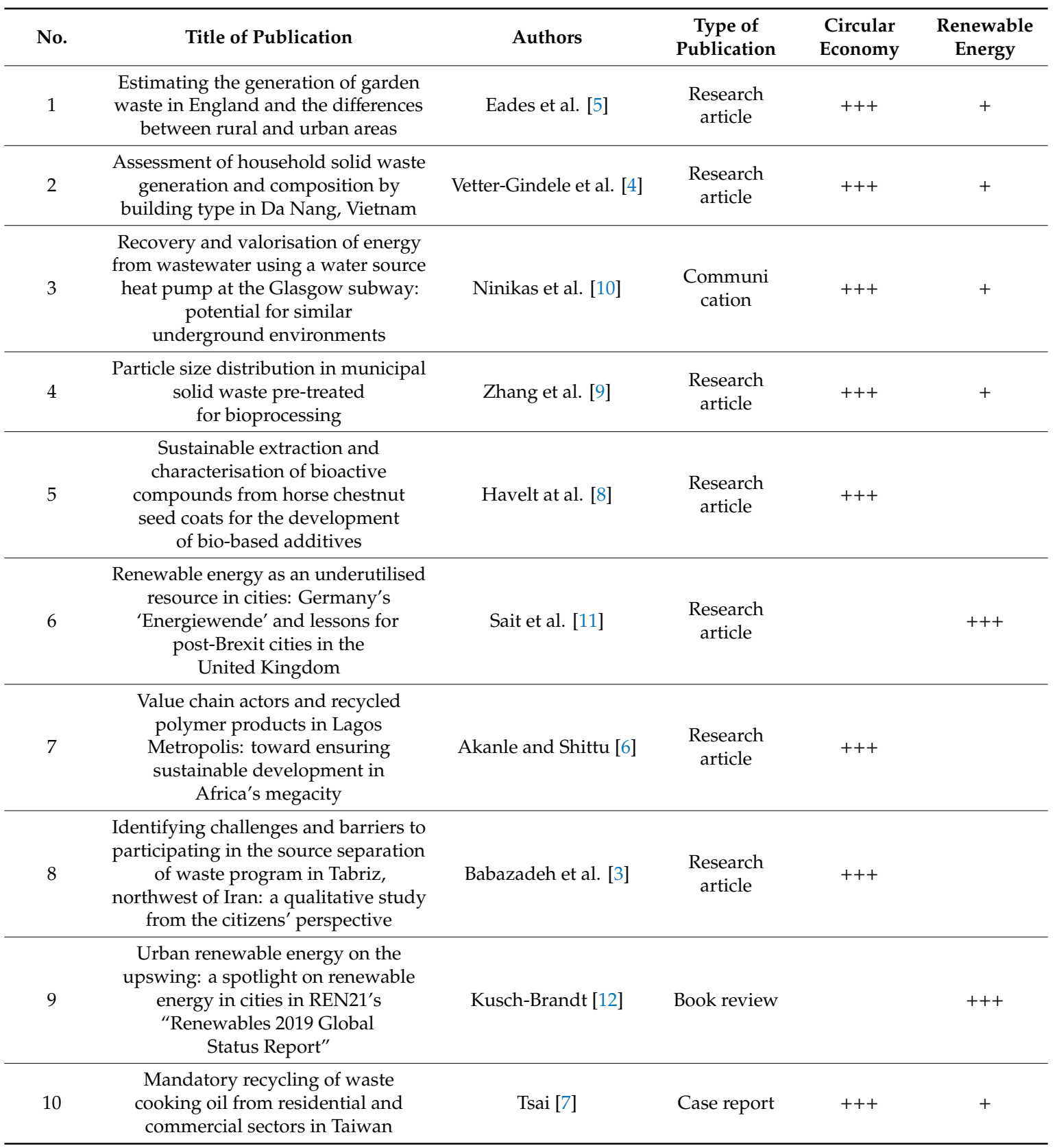


It is interesting to note that none of the publications addresses underutilised resources in the urban-rural context, although the Special Issue's information website [13] and the invitation to submit a paper explicitly also mentioned a specific interest in studies that explore the urban-rural context. Only the work of Eades et al. [5] considers the rural sector by looking at differences between urban and rural areas, but none of the publications study urban-rural linkages. The relative lack of an integrated urban-rural perspective may fuel the concern that strong emphasis on urban issues risks further marginalising the rural perspective [14], but caution is due when drawing such conclusion because, unquestionably, this Special Issue does not reflect the full scope of research related to urban resources. While certainly not all topics relevant in the field of urban resource management are covered, the included publications paint a multifaceted picture of opportunities and challenges related to resources in urban environments.

Source separation of household waste into recyclable fractions is a prerequisite for making available waste components as valuable resources, and it is also a public health concern. The study of Babazadeh et al. [3] illustrates that, in practice, several challenges exist in a developing country such as Iran to achieve participation of citizens in source separation programmes for household waste. Their qualitative research, which included interviewing inhabitants of the city of Tabriz, identified four core categories of problems, namely insufficient awareness about the system among citizens, lack of responsibility among the population, an expectation of receiving incentives and problems in the collection system itself, such as inappropriate bins. These results show that the user-friendly design of collection systems is an important step, but the findings also highlight that awareness and motivation of citizens are most essential elements to achieve participation of households and thus enable the recovery of valuable secondary resources in practice.

Even basic information about the quantities and composition of household solid waste is not necessarily available in many cities, which is a specific challenge in planning waste management and recycling systems where population numbers are further growing. This was the starting point of Vetter-Gindele et al. [4], who selected the city of Da Nang in Vietnam for their project. They developed and tested a method to assess quantity and composition of household waste through a combination of geospatial data analyses and empirical analyses-more precisely, they combined high-resolution satellite imagery, surveys and on-site solid waste analyses. The researchers clustered the data by five building types and used satellite images to estimate building distributions across the entire city. Their study concluded that building type can be reasonably well used as a proxy for the socioeconomic conditions of the inhabitants and thus their waste generation.

However, not only developing countries struggle to have available precise information about the valuable materials present in waste flows. One example is garden waste arising in private households. Garden waste is a high-volume material stream which can be used to produce compost or for energy generation, but quantities are not well known, and quantification is methodologically challenging. Statistics in Europe only consider those quantities which are collected from the property, either as segregated green waste or a mixed biowaste stream, but householders can also make use of home composting and burning. Eades et al. [5] surveyed 798 properties in England, using a combination of interviews and measurements, and estimated that around 70\% of garden waste in England enters the collection schemes of the waste management authorities. Significant differences exist, however, between urban and rural households. In the study of Eades et al. [5], urban households largely relied on official collection schemes, while in rural areas more than half of the generated quantities of garden waste were subjected to self-sufficient methods, including large quantities burned, which is not a sustainable practice. Another concern is fly tipping of garden waste into the local environment.

A further valuable solid waste material stream are polymer products. Plastics today are ubiquitous, and their recovery is a key step to save primary resources and avoid plastic pollution, including marine litter. Akanle and Shittu [6] examined the value chain of polymer recycling in the African megacity Lagos Metropolis, Nigeria, based on interviewing different stakeholders and implementing a field survey among 400 residents. Polymer recycling contributes to environmental protection and it can be an 
important source of income generation because it provides numerous opportunities for entrepreneurs, but the potential in Lagos remains largely unexploited. Alkanle and Shittu [6] identify several factors that hinder effective polymer recycling schemes on a large scale, including poor social perception of activities related to waste management along with the fear of social exclusion, health implications, a lack of adequate information and unfavourable governmental policies. The authors formulate recommendations how to overcome these barriers. The findings of this work are similar to the observations made by Babazadeh et al. [3], insofar that it is not sufficient to solely focus on technology and infrastructure, because motivational factors, knowledge and social perception also play a major role in implementing effective solid waste management and recycling schemes.

Tsai [7] presents a case study on recycling waste cooking oil in Taiwan. This material occurs in considerable quantity from the cooking processes for human daily meal preparation. It represents a low-cost feedstock for the production of biodiesel and biobased products. In Taiwan, waste cooking oil was designated a mandatory recyclable resource in 2015. Since then, collected and recycled quantities have been drastically increased in response to changed legal regulations. This illustrates that effective regulatory frameworks have a decisive impact on increasing the share of secondary resources. The author also provides an overview of currently available valorisation pathways for waste cooking oil. The results of this study are not only relevant for Taiwan but are transferable to other regions.

A very different material stream was studied by Havelt et al. [8]. They used horse chestnut seed coats, a residue of the pharmaceutical industry which occurs in significant quantities because the industry uses only the peeled seeds to extract valuable ingredients. The researchers successfully extracted high-value target components from the seed coats. These components can serve as additives in food packaging manufacturing, in order to optimise the characteristics of the packaging and therefore increase product shelf life. Different extraction techniques were applied and tested. The work of Havelt et al. [8] includes a characterisation of the obtained extracts. The researchers concluded that their proposed processing represents an ecologically and economically favourable solution for managing this type of pharmaceutical waste with added value. The developed process can also be applied to whole horse chestnut seeds.

Better characterisation of a valuable urban material is also the topic of interest in the publication of Zhang et al. [9]. Their work focuses on the organic fraction of municipal solid waste. More specifically, the authors study organic waste obtained as a fraction from mixed municipal solid waste in mechanical-biological treatment (MBT) plants, i.e. after the application of different treatments to condition the material and recuperate recyclable fractions. The organic fraction is destined for the bioprocessing step of the MBT installation, which is composting or anaerobic digestion. The work studies the particle size distribution in organic waste and applies different pre-treatments to influence the particle size distribution. Particle size is a relevant parameter that impacts the performance of bioprocessing; however, there is no generally optimal particle size, because the different bioprocessing schemes benefit from different particle sizes.

The publication of Ninikas et al. [10] introduces a new perspective to the Special Issue. The above-discussed contributions focus on the valorisation of a specific solid material stream, while Ninikas et al. [10] study energy valorisation, namely the valorisation of waste heat contained in urban wastewater, which usually is not given attention. The researchers successfully recovered energy from wastewater using a water heat pump and they implemented a valorisation scheme in the subway system of Glasgow. This makes a relevant contribution to primary energy saving and to circular economy implementation in urban areas. Their work highlights the potential to replicate the solution in many other cities with a metro system. The publication also explores challenges for widespread implementation of the solution.

The focus on sustainable energy systems is strengthened with two more publications, and both contributions put an explicit spotlight on renewable energy as a still underutilised but increasingly important resource in cities. Sait et al. [11] draw lessons from evaluating the adoption of renewable energies in the three German cities Munich, Berlin and Freiburg. They generalise their observations 
and apply them to make recommendations for managing energy transition in UK cities after Brexit. The policy system approach to energy governance can facilitate innovation and responsible governance, and the authors argue that it is essential to consider an integrated framework under inclusion of socio-economic impacts of policy decisions. Understanding the power balance between stakeholders, community engagement and trust in policymaking processes are considered essential elements [11].

The book review of Kusch-Brandt [12] highlights that renewable energy in cities is already increasingly being exploited worldwide. The review summarises the contents of the most recent edition of the Renewables Global Status Report, published by the Renewable Energy Policy Network for the 21st Century (REN21) [15]. The Renewables Global Status Report is updated each year and it is one of the most comprehensive and authoritative resources for academic and non-academic readers in the search for up-to-date information about the status of renewable energies. The 2019 edition, as a unique feature, has included an extra section about renewable energies in cities, acknowledging the fact that cities are increasingly becoming important players in renewable energy deployment, while also holding key responsibility because cities account for two-thirds of global energy demand $[15,16]$. More than 100 cities worldwide already cover at least 70\% of their electricity demand with renewables [15]. Many cities have set highly ambitious targets for renewables. It is worth mentioning that REN21 has now published a special report fully dedicated to renewables in cities [17].

\section{Concluding Remarks}

The circular economy and renewable resources today already play an important role in making cities more sustainable. The studies presented in this Special Issue are a rich source to explore promising urban resource management solutions and to understand the challenges and potential barriers. The publications also identify further research needs. It is hoped that this Special Issue contributes to accelerating progress towards sustainable development and the reader is invited to study the individual publications in detail.

Funding: This research received no external funding.

Acknowledgments: I thank the editorial team of Resources, Sammy Wang and Mindy Wang in particular, for the chance to make this Special Issue of the journal Resources happen and for the continuous support towards compiling this set of publications. Special thanks also go to the reviewers who have devoted their time and expertise to assess the quality of submitted manuscripts and to provide valuable feedback to the authors.

Conflicts of Interest: The author declares no conflict of interests.

\section{References}

1. UN DESA. World Population Prospects 2019: Highlights; United Nations, Department of Economic and Social Affairs, Population Division: New York, NY, USA, 2019. Available online: https://population.un.org/wpp/ Publications/Files/WPP2019_Highlights.pdf (accessed on 6 March 2020).

2. IRP. The Weight of Cities: Resource Requirements of Future Urbanization; International Resource Panel, United Nations Environment Programme: Nairobi, Kenya, 2018. Available online: https://www.resourcepanel.org/sites/default/files/documents/document/media/the_weight_of_cities_ full_report_english.pdf (accessed on 6 March 2020).

3. Babazadeh, T.; Nadrian, H.; Mosaferi, M.; Allahverdipour, H. Identifying Challenges and Barriers to Participating in the Source Separation of Waste Program in Tabriz, Northwest of Iran: A Qualitative Study from the Citizens' Perspective. Resources 2018, 7, 53. [CrossRef]

4. Vetter-Gindele, J.; Braun, A.; Warth, G.; Bui, T.T.Q.; Bachofer, F.; Eltrop, L. Assessment of Household Solid Waste Generation and Composition by Building Type in Da Nang, Vietnam. Resources 2019, 8, 171. [CrossRef]

5. Eades, P.; Kusch-Brandt, S.; Heaven, S.; Banks, C.J. Estimating the Generation of Garden Waste in England and the Differences between Rural and Urban Areas. Resources 2020, 9, 8. [CrossRef]

6. Akanle, O.; Shittu, O. Value Chain Actors and Recycled Polymer Products in Lagos Metropolis: Toward Ensuring Sustainable Development in Africa's Megacity. Resources 2018, 7, 55. [CrossRef] 
7. Tsai, W.-T. Mandatory Recycling of Waste Cooking Oil from Residential and Commercial Sectors in Taiwan. Resources 2019, 8, 38. [CrossRef]

8. Havelt, T.; Brettschneider, S.; Do, X.T.; Korte, I.; Kreyenschmidt, J.; Schmitz, M. Sustainable Extraction and Characterisation of Bioactive Compounds from Horse Chestnut Seed Coats for the Development of Bio-Based Additives. Resources 2019, 8, 114. [CrossRef]

9. Zhang, Y.; Kusch-Brandt, S.; Gu, S.; Heaven, S. Particle Size Distribution in Municipal Solid Waste Pre-Treated for Bioprocessing. Resources 2019, 8, 166. [CrossRef]

10. Ninikas, K.; Hytiris, N.; Emmanuel, R.; Aaen, B. Recovery and Valorisation of Energy from Wastewater Using a Water Source Heat Pump at the Glasgow Subway: Potential for Similar Underground Environments. Resources 2019, 8, 169. [CrossRef]

11. Sait, M.A.; Chigbu, U.E.; Hamiduddin, I.; De Vries, W.T. Renewable Energy as an Underutilised Resource in Cities: Germany's 'Energiewende' and Lessons for Post-Brexit Cities in the United Kingdom. Resources 2019, 8, 7. [CrossRef]

12. Kusch-Brandt, S. Urban Renewable Energy on the Upswing: A Spotlight on Renewable Energy in Cities in REN21's "Renewables 2019 Global Status Report”. Resources 2019, 8, 139. [CrossRef]

13. Special Issue "Underutilised Resources in Urban Environments". Available online: https://www.mdpi.com/ journal/resources/special_issues/underutilised_resources (accessed on 6 March 2020).

14. Kusch, S.; Fleming, A.; Cradock-Henry, N.; Schmitz, N.; Pereira, L.; Vogt, J.; Lim, M.; Kharrazi, A.; Evoh, C.J.; Hamel, P.; et al. Sustainability in a Changing World: Integrating Human Health and Wellbeing, Urbanisation, and Ecosystem Services. Brief for the UN Global Sustainable Development Report. 2016. Available online: https://sustainabledevelopment.un.org/content/documents/9490Brief\%20GSDR2016\% 20FE\%20Fellows\%20Nexus.pdf (accessed on 6 March 2020).

15. REN21. Renewables 2019 Global Status Report; REN21 Secretariat: Paris, France, 2019; ISBN 978-3-9818911-7-1. Available online: http://www.ren21.net/gsr-2019/ (accessed on 26 July 2019).

16. IEA (International Energy Agency). Cities Are at the Frontline of the Energy Transition. 7 September 2016. Available online: https://www.iea.org/newsroom/news/2016/september/cities-are-at-the-frontline-of-theenergy-transition.html (accessed on 26 July 2019).

17. REN21. Renewables in Cities 2019 Global Status Report; REN21 Secretariat: Paris, France, 2019; ISBN 978-3-9818911-9-5. Available online: https://www.ren21.net/reports/cities-global-status-report/ (accessed on 7 March 2020). 